\title{
Uma revisão de literatura sobre o neoinstitucionalismo e a avaliação do desempenho de instituições sociais
}

\author{
Roberto de Sousa Miranda ${ }^{1}$
}

\begin{abstract}
1 Pós-Doutorado na Universitat Autònoma de Barcelona, em andamento, Doutor em Ciências Sociais, Mestre em Sociologia e Graduado em Ciências Sociais pela Universidade Federal de Campina Grande. Professor do Programa de Pós-Graduação em Ciências Sociais e da Unidade Acadêmica de Ciências e Tecnologia Ambiental da Universidade Federal de Campina Grande, Brasil. E-mail: robertosmiranda@yahoo.com.br
\end{abstract}

RESUMO: A avaliação do desempenho de instituições sociais informais, formais, públicas e privadas vem sendo realizado constantemente, em muitos casos de modo pouco criterioso. A fim de contribuir para o aprimoramento teórico e metodológico desse campo de pesquisa, se propõe uma revisão da literatura que trata do neoinstitucionalismo, abordagem que resgata os estudos das instituições nas ciências sociais. O esforço de problematização da dinâmica institucional parte da discussão das abordagens institucionais, as velhas e as novas, e uma abordagem comportamental, a teoria da escolha racional, fazendo as críticas pertinentes e, assim, marcando posições e apresentando as estratégias teóricas e metodológicas que possibilitam a análise do desempenho das instituições sociais. As instituições exercem um papel importantíssimo em nossa vida cotidiana, nas relações: entre familiares e amigos, que têm a reciprocidade como aspecto preponderante; com o mercado, que são orientadas pela formalização de contratos; e, especialmente, com o Estado, que elabora os principais arranjos institucionais voltados para a regulação e regulamentação de vários espectros da sociedade.

Palavras-chave: Instituições Sociais; Neoinstitucionalismo; Desempenho Institucional.

\section{A review of literature on neo-institutionalism and measuring of social institutions performance}

ABSTRACT: The performance measuring of informal social institutions, formal, public and private has been held continuously, in many cases so little careful. To contribute to the improvement of the field theoretical and methodological research proposes a review of the literature dealing with the neo-institutionalism, an approach that rescues studies in institutions in the social sciences. The effort to problematization of the institutional dynamics part of the discussion of institutional approaches, old and new, and a behavioral approach, the rational choice theory, making pertinent criticism and thus marking positions and presenting the theoretical and methodological strategies that enable analysis of the performance of social institutions. Institutions exert an important role in our everyday life, in relationships: between family members and friends who have reciprocity as very important aspect, with the market, which are guided by formal contracts, and especially with the State that produces the major institutional arrangements aimed to regulating and regulating the various spectrums of society.

Keywords: Social Institutions; Neo-institutionalism; Institutional Performance.

\section{INTRODUÇÃO}

Partindo da ideia de que as instituições canalizam as escolhas sociais (DIMAGGIO; POWELL, 1999) e garantem a promoção dos interesses dos seus membros (OLSON, 1999), inicia-se uma revisão da literatura que trata do neoinstitucionalismo - perspectiva teórica que analisa o desempenho de instituições sociais (informais, formais, 
públicas e privadas), os processos de tomada de decisões, a mediação entre os atores sociais e os representantes dos poderes públicos, e a elaboração e a execução de políticas públicas voltadas para a consolidação de espaços públicos destinados à participação e/ou para o desenvolvimento local - para apresentar o seu processo de construção e a sua trajetória, de modo, que se possa ter clareza dos seus usos e das suas fragilizadas analíticas.

Nos Estados Unidos e na Europa o debate teórico e metodológico em torno do neoinstitucionalismo é intenso e de longa data, no Brasil são raros os trabalhos que realizam esse esforço, exceção feita a Marques (1997) e Miranda (2007), muito embora pesquisas sobre o poder legislativo (MONTEIRO, MONTEIRO; LIMA, 2001; PERES; CARVALHO 2012), as políticas públicas (CAVALCANTE, 2011; MENDES; CODATO, 2015; VIEIRA; GOMES, 2014) e a avaliação de desempenho institucional (FERNANDES, 2002; FELISBERTO, 2006; CANIELLO, PIRAUX; BASTOS, 2012; MACKE; SARATE, 2015) tenham o neoinstitucionalismo como referencial, às vezes sem saberem, especialmente quando adotam de maneira isolada o conceito de capital social de Putnam (2002).

Enquanto perspectiva teórica, as origens do institucionalismo remontam ao início do século $X X$, momento em que nas ciências sociais, especificamente na Ciência Política, estudiosos se dedicaram a análise dos sistemas políticos e das formas de governo, para diferenciar os bons dos maus governos. Esses trabalhos eram, em sua maioria, análises descritivas e históricas, o que lhes renderam várias críticas, muitas relacionadas à fragilidade teórica e metodológica. Deste modo, para diferenciá-lo das perspectivas institucionais atuais costuma-se denominá-lo de velho institucionalismo ou institucionalismo clássico (DIMAGGIO; POWELL, 1999; ROMERO, 1999).

Em virtude do seu caráter descritivo e histórico o institucionalismo clássico era considerado uma perspectiva sem teoria, por não permitir a realização de comparações que permitissem generalizações. A fim de preencher essas lacunas e mudar o foco analítico, desenvolveram-se nas ciências sociais as abordagens comportamentais, com destaque para a teoria da escolha racional, e o estruturo-funcionalismo (PETERS, 2003; PERES, 2008). O estudo das instituições ressurge nas ciências sociais apenas nas décadas de 1960 e de 1970, em resposta a essas duas abordagens (HALL; TAYLOR, 2003; PETERS, 2003).

A análise das configurações institucionais se intensifica nas ciências sociais a partir dos anos 1980 e 1990, quando o papel das instituições no desenvolvimento e na coordenação de ações que necessitam da cooperação mútua, passa a ser considerado preponderante. No Brasil, pode-se verificar a formação de instituições nas várias esferas sociais: nos municípios formaram-se os conselhos responsáveis pela fiscalização e pela formulação de políticas públicas; na sociedade civil, as associações e as ONGs desempenham os mais variados papeis.

Para facilitar a leitura e o entendimento, o texto está organizado em quatro partes. A primeira trata do institucionalismo clássico e da teoria da escolha racional, ressaltando os aspectos pré-estruturantes do neoinstitucionalismo ${ }^{1}$. A segunda apresenta o neoinstitucionalismo e seus diferentes métodos de análise, fazendo uma comparação entre

\footnotetext{
${ }^{1} \mathrm{O}$ termo neoinstitucionalismo foi cunhado por March e Olsen (1984).
} 
os mesmos. A terceira aborda o institucionalismo da escolha racional, especificamente, a união entre uma abordagem institucional e uma comportamental. E por fim, na quarta parte é realizada a problematização da dinâmica do desempenho institucional.

\section{O INSTITUCIONALISMO CLÁSSICO E A TEORIA DA ESCOLHA RACIONAL}

O institucionalismo clássico dedicou-se fundamentalmente ao estudo dos detalhes que configuravam as diferentes estruturas administrativas, legais e públicas (ROMERO, 1999). Os trabalhos produzidos eram densamente normativos e as escassas análises comparativas feitas eram, em sua maioria, descrições justapostas de diversas configurações institucionais em países distintos, comparando-as e contrastando-as. Esse enfoque não permitia a construção de categorias analíticas e conceitos que proporcionassem uma investigação autenticamente comparativa e que pudessem abrir espaço para uma teoria explicativa (PETERS, 2003).

Apesar de ser considerada, pelos críticos da época, uma abordagem sem base teórica e descritiva, o institucionalismo clássico se caracterizou por cinco pontos principais, que, de certa maneira, contribuíram para o surgimento do novo institucionalismo: (1) o legalismo, ênfase dada às leis e ao papel central que tinham na atividade governamental, assim, estudar instituições políticas resumia-se à análise da legislação do país; (2) o estruturalismo ${ }^{2}$, a estrutura enquanto determinante do comportamento individual; (3) o historicismo, forte fundamentação

\footnotetext{
${ }^{2} \mathrm{O}$ estruturalismo do institucionalismo clássico se concentrou em observar as principais características institucionais dos sistemas políticos, parlamentarismo e presidencialismo (PETERS, 2003).
}

histórica das pesquisas; e (4) as análises normativas, descrições acerca da política com preocupações sobre um bom governo (PETERS, 2003).

Em contraposição ao institucionalismo clássico surgem nos anos de 1950, propostas analíticas alternativas, especialmente, na Economia e na Ciência Política, marcadas: (1) pela preocupação com a teoria e a metodologia; (2) pela tendência antinormativa; (3) pelo individualismo metodológico, o centro das análises são os indivíduos que tomam decisões; e (4) por um enfoque sistêmico, concentração do foco nos inputs e outputs (DIMAGGIO; POWELL, 1999; PETERS, 2003; ROMERO, 1999). Dentre essas propostas destaca-se a teoria da escolha racional $^{3}$ (ARROW, 1951; DOWNS, 1999) -, que focaliza as intencionalidades, as incertezas, os riscos e a racionalidade dos indivíduos (BAERT, 1997):

a) intencionalidades. As explicações são formadas por um subconjunto de explicações intencionais que tentam dar conta das práticas sociais dos indivíduos por meio de referências às finalidades e aos objetivos. As ações intencionais são acompanhadas de consequências não intencionais, o dilema do prisioneiro ${ }^{4}$ é o exemplo clássico de ação intencional que produz um resultado não

\footnotetext{
${ }^{3}$ Alguns teóricos da escolha racional defendem que as metodologias de Tocqueville (BOUDON, 1995 e 1998) e Marx (ELSTER, 1989) ocultam perspectivas da escolha racional.

${ }^{4} \mathrm{O}$ dilema do prisioneiro conta que "dois prisioneiros suspeitos de um crime violento são mantidos em celas diferentes, e a cada um é oferecido o seguinte acordo pelo promotor: Se você confessar e o outro prisioneiro não o fizer, você será libertado; se o outro prisioneiro também confessar, você receberá uma sentença moderada. Se nenhum de vocês confessar, vocês receberão sentença menor do que se ambos confessarem; se o outro confessar, mas você não, você receberá a sentença máxima" (TSEBELIS, 1998, p. 69).
} 
intencional: subótimo.

b) incerteza e risco. Frequentemente as pessoas têm informações imperfeitas ou incompletas, resultantes da diferença entre incerteza e risco. Ao enfrentarem situações de risco, as pessoas são capazes de atribuir probabilidades aos vários resultados, ao passo que, confrontadas com situações de incerteza não são capazes de fazê-lo. Assim, os indivíduos são capazes de calcular a utilidade esperada ou o valor esperado de cada ação quando se deparam com situações de risco.

c) racionalidade. Ao interagirem, os indivíduos procuram maximizar os benefícios e minimizar os custos envolvidos em suas ações. Isso pressupõe que o indivíduo participante da ação seja capaz de estabelecer um ordenamento completo das alternativas, criando uma função de utilidade que facilita calcular cada uma das alternativas disponíveis, a partir da relação custo benefício, e eleger as melhores estratégias a serem adotadas.

O conceito de racionalidade, alicerçado em bases utilitarista e econômica (ZAFIROVSKI, 1999), tem sido o calcanhar de Aquiles da teoria da escolha racional. Os debates são polarizados entre os autores que trabalham com a ideia de uma racionalidade completa (ELSTER, 1994; FEREJOHN; PASQUINO, 2001; TSEBELIS, 1998) e os que defendem uma racionalidade limitada (BAERT, 1997; BOUDON, 1998; KATO, 1996; OSTROM, 1998; ZAFIROVSKI, 1999), na tentativa de ampliar o foco de análise e, assim, incorporar aspectos sociais e culturais, comumente desconsiderados.

Duas conceituações de racionalidade que se propõem a serem completas são a de Tsebelis (1998) e a de Ferejohn e Pasquino (2001). Para o primeiro a racionalidade é entendida como uma correspondência ótima entre fins, mediante a distinção entre exigências fracas de racionalidade (coerência interna entre preferências e crenças) e exigências fortes de racionalidades (correspondência das crenças com a realidade). Para o segundo a racionalidade é como uma ação escolhida entre os melhores atos disponíveis para o indivíduo, dadas as suas crenças e os seus desejos.

As críticas feitas à racionalidade completa partem do pressuposto de que os indivíduos nem sempre possuem as informações precisas para realizarem as melhores escolhas e, assim, maximizarem seus ganhos. Ostrom (1998) propõe modelos de racionalidade fundamentados na aprendizagem de normas e regras e na reciprocidade. Zafirovski (1999), o conceito de racionalidades múltiplas, que se refere aos propósitos que orientam as ações e escolhas dos indivíduos, prestígio social e questões religiosas, por exemplo. Boudon (1998) propõem dois tipos de racionalidade alternativos - extraídos das propostas teóricas de Tocqueville e Weber - a racionalidade cognitiva, não instrumental, e a racionalidade axiológica.

O institucionalismo clássico, ao prestigiar os elementos estruturais dos governos e os normativos, e a teoria da escolha racional, ao se deter à análise das decisões dos indivíduos, embora tenham recebido muitas críticas e sugestões de redefinições conceituais, acabaram contribuindo para a retomada do debate sobre a importância das instituições na vida social nos anos de 1960 e, especialmente, nos anos 1980, com a formulação de novas abordagens institucionais, chamadas genericamente de neoinstitucionalistas. 
3 NEOINSTITUCIONALISMO E SEUS DIFERENTES MÉTODOS DE ANÁLISE

O estudo das instituições renasce nas ciências sociais, nos anos de 1960, em reação à teoria da escolha racional (DIMAGGIO; POWELL, 1999; PETERS, 2003) e ao estruturo-funcionalismo (HALL; TAYLOR, 2003). Marca o retorno da Ciência Política às suas raízes acadêmicas (PETERS, 2003) e um esforço das ciências sociais de adquirirem respostas novas a perguntas antigas: como os arranjos institucionais mediam e canalizam as escolhas sociais? (DIMAGGIO; POWELL, 1999).

Essa retomada é caracterizada pelo desenvolvimento do neoinstitucionalismo, que não se constitui uma abordagem unificada. Não há um consenso na academia sobre a quantidade de abordagens existentes. Kato (1996) fala em três metodologias: (1) uma tradicional que realiza análises históricas ou qualitativas para determinar os fatores e dinâmicas de mudança institucional; (2) uma vinculada às teorias da escolha racional; e (3) a que analisa a relação entre instituições políticas e indivíduos baseandose no conceito de bounded rationality.

Peters (2003) assinala a existência de pelo menos sete versões: o institucionalismo normativo, o institucionalismo da escolha racional, o institucionalismo histórico, o institucionalismo empírico, o institucionalismo sociológico, o institucionalismo de representação de interesses e o institucionalismo internacional. Contudo, a divisão mais aceita é a de Hall e Taylor (2003), que atestam a existência de três versões: o institucionalismo histórico, o institucionalismo da escolha racional e o institucionalismo sociológico.

A análise da literatura neoinstitucional mostra que, apesar da diversidade, pode-se falar em quatro abordagens: o institucionalismo normativo, o institucionalismo histórico, o institucionalismo da escolha racional e o institucionalismo sociológico. A análise dessas abordagens partirá de quatro questionamentos que serão feitos a cada uma delas: O que são instituições? Como as instituições surgem? Como explicam os processos de mudanças institucionais? Como tratam a relação entre indivíduos e instituições?

\subsection{0 que são instituições?}

O institucionalismo normativo define instituições como:

Political institutions are collections of interrelated rules and routines that define appropriate actions in terms of relations between roles and situations. The process involves determining what the situation is, what role is being fulfilled, and what are. (MARCH; OLSEN, 1989, p. 160).

Essa definição parte do pressuposto de que uma instituição define um conjunto de comportamentos (reforça os comportamentos adequados para os papeis e sanciona as inadequações), podendo ser aplicados a todos os membros da instituição ou específicos às posições ocupadas pelos indivíduos dentro da instituição. A finalidade do conceito de papel é vincular a conduta individual à instituição. Nesse sentido, as instituições sociais também podem ser definidas pela sua durabilidade e pela sua capacidade de influenciar a conduta dos indivíduos no decorrer do tempo (PETERS, 2003).

$\mathrm{O}$ institucionalismo histórico define as instituições a partir de exemplos que vão 
desde estruturas governamentais formais, passando por instituições legais, até instituições sociais vinculadas à sociedade civil, usando este conjunto de estruturas distintas para explicar os fenômenos políticos (PETERS, 2003). Essa definição é ampla e engloba "procedimentos, protocolos, normas e convenções oficiais e oficiosas inerentes à estrutura organizacional da comunidade política ou da economia política" (HALL; TAYLOR, 2003, p. 196).

Para o institucionalismo histórico as instituições fornecem modelos morais e cognitivos que permitem a interpretação e a ação. Nesse sentido, o indivíduo é concebido como uma entidade pertencente a um mundo de instituições composto de símbolos, de cenários e de protocolos que fornecem filtros para que sejam feitas interpretações que possibilitem a definição das ações dos indivíduos.

O institucionalismo da escolha racional define instituições como:

(...) rules of the game in a society or, more formally, are the humanly devised constrains that shape human interaction. In consequence they structure incentives in human exchange, whether political, social, or economic (NORTH, 1990, p. 3).

ou como regulamentações usadas para determinar: quem participa dos processos de tomada de decisão; quais as medidas podem ser adotadas e em qual sequência; e, como se integram as ações individuas e as coletivas. Em suma, seria tudo o que é compartilhado internamente numa comunidade ou grupo social (KISER; OSTROM, 1982).

Os teóricos do institucionalismo sociológico defendem que as instituições são es- truturas e atividades cognitivas, normativas e reguladoras que dão estabilidade e significado ao comportamento social. O que não permite uma distinção clara entre instituições e organizações. A partir de uma analogia é possível propor uma diferenciação: as organizações seriam como equipes que se enfrentam em uma partida e as instituições seriam as regras que regem esse esporte, ou seja, as organizações se formam para participar do entorno institucional, criado por mercados e sistemas políticos (PETERS, 2003).

\subsection{Como são formadas as instituições?}

Para o institucionalismo normativo, as instituições derivam parte de sua estrutura de significação de procedimentos operacionais padrões presentes na sociedade dentro da qual se formam (MARCH; OLSEN, 1989). $\mathrm{Na}$ maioria dos casos, quando os indivíduos são introduzidos numa instituição, já foram previamente socializados pela sociedade, pois normas comuns como reciprocidade, honestidade e cooperação, são aprendidas no processo geral de socialização e se tornam rotinas. Desta maneira, à medida que as rotinas são fortalecidas e adquirem um maior significado, aumenta o grau de institucionalização.

Essa definição apresenta dois pontos de limitação. Primeiro, quando ingressa numa instituição, o indivíduo traz diversos valores, por conseguinte, os resultados podem não ser satisfatórios em instituições que possuam normas e valores muito diferentes dos encontrados na sociedade. O segundo se refere à possibilidade dos indivíduos interagirem para a criação das rotinas que surgem quando as instituições são formadas (PETERS, 2003), no entanto, o institu- 
cionalismo normativo não enfatiza o processo inicial de institucionalização.

O institucionalismo histórico não se detém à formação das instituições, mas, às que já estão formadas. Contudo, a ênfase que é dada às estruturas que sustentam as instituições sugere uma definição. Quando uma ideia chega a ser aceita e a penetrar na estrutura social, pode-se dizer que uma instituição foi criada. Esta conceituação, juntamente com a elaborada pelo institucionalismo normativo, não apresentam muita consistência e clareza, porque focaliza o momento de criação e não o processo que desencadeia o mesmo.

O institucionalismo da escolha racional explica bem o que é uma instituição, porém, não elucida da mesma maneira o processo de criação. As instituições surgem a partir de (1) acordos voluntários entre atores sociais interessados na aquisição de benefícios que não poderiam ser adquiridos individualmente; ou (2) pelos órgãos públicos interessados na criação de mecanismos que inibam comportamentos egoísticos que colocam a coletividade em risco. Em ambos os casos o pano de fundo é a promoção do interesse comum a partir da cooperação.

O processo de criação das instituições para o institucionalismo sociológico é singular, quando comparado com as demais abordagens institucionais, e não é suficientemente claro. A explicação toma como base a ação de indivíduos que se apropriam de modelos institucionais já existentes no mundo institucional, que circunscrevem a quantidade de criações possíveis. Uma explicação confusa por não considerar que a criação de instituições envolve conflitos entre os atores sociais (HALL; TAYLOR, 2003) que possuem interesses diferentes.

\subsection{Como explicam os processos de mu- dança institucional?}

Para o institucionalismo normativo, o processo de mudança institucional é um dos elementos mais fortes e persuasivos. As instituições possuem uma série de respostas (rotinas) para os problemas, que são usadas antes de se buscar alternativas que se afastem dos valores básicos da instituição. As mudanças institucionais postas em prática, portanto, são adaptadas aos valores institucionais. $O$ institucionalismo normativo aponta a existência de vários estímulos para a mudança institucional, porém, o mais importante deles é o processo de aprendizagem, como principal meio para a adaptação (PETERS, 2003).

O ponto mais problemático do institucionalismo histórico é a explicação da mudança institucional. Ao defender que as decisões políticas anteriores influenciam fortemente os resultados das decisões políticas atuais, esses teóricos estão defendendo, talvez inconscientemente, que as decisões institucionais e políticas iniciais possuem efeitos duradouros. Desta maneira, o institucionalismo histórico explica melhor a persistência de normas e regras do que a mudança das instituições. Ao tentar explicar a mudança institucional o faz por meio de conceito de equilibrios intermitentes (PETERS, 2003).

Para o institucionalismo da escolha racional, grosso modo, a mudança institucional ocorre quando a instituição não consegue desempenhar, adequadamente, as tarefas para as quais foi criada (HALL; TAYLOR, 2003). O institucionalismo sociológico conceitua o processo de mudança institucional de duas maneiras: (1) por meio da institucionalização que aumenta a quanti- 
dade de características da instituição, tornando mais firmes os marcos cognitivos, o que possibilita a mudança, ou pela desinstitucionalização que reduz os marcos cognitivos, e modifica a instituição; (2) a outra assinala que as instituições devem encontrar meios para se adaptar a todas as mudanças do seu entorno, que podem ocasionar mudanças institucionais.

\subsection{Como tratam a relação entre indivíduos e instituições?}

O institucionalismo normativo considera que as instituições necessitam de mecanismos que moldem os comportamentos individuais, e outro que permita aos indivíduos formarem e reformularem as instituições (PETERS, 2003). Caso isso não ocorra, as instituições passam a ser entidades abstratas com pouca relação com o comportamento político. Essa vinculação é decorrente dos procedimentos operacionais padrões que define qual é o comportamento mais adequado para os membros da instituição e quais não são. Entretanto, é necessária a existência de mecanismos eficazes que permitam a imposição de sanções que desestimulem a violação das regras $(\mathrm{MARCH}$; OLSEN, 1989).

Outro aspecto que diferencia o institucionalismo histórico das demais versões, principalmente do institucionalismo da escolha racional, é a maneira como trata a relação entre indivíduos e instituições. $O$ indivíduo é passivo, quando escolhe ser membro de uma instituição, aceita as restrições que the são impostas (HALL; TAYLOR, 2003). É como se as decisões, uma vez tomadas, funcionassem em piloto automático, enquanto a conduta individual é modificada por ações que os membros to- maram anos atrás. É por isso que as instituições se apresentam estáveis ao longo do tempo (PETERS, 2003).

O institucionalismo da escolha racional elaborou uma concepção precisa das relações entre indivíduos e instituições (HALL; TAYLOR, 2003). As instituições moldam a conduta dos indivíduos, e os indivíduos moldam o comportamento das instituições, por se constituírem as causas das atividades institucionais. Além disso, as análises desta abordagem dão espaço, considerável, à intencionalidade humana na determinação das situações políticas, a partir de cálculos estratégicos que levam em consideração as variáveis estruturais.

Um dos grandes problemas do institucionalismo sociológico é a maneira como aborda a relação entre indivíduos e instituições. Existem dois debates dominantes entre os teóricos desta abordagem: (1) de um lado, estão os que defendem que as instituições são, fundamentalmente, uma manifestação simbólica das necessidades de legitimação de uma sociedade ou de um grupo social, desse modo, podem ser consideradas separadamente da ação dos participantes (MEYER; ROWAN, 1977); (2) de outro, os que defendem que as instituições só passam a existir quando moldam o comportamento dos seus membros ${ }^{5}$ (PETERS, 2003).

\section{TEORIA DA ESCOLHA RACIONAL E TEORIA INSTITUCIONAL}

A literatura que trata da teoria da escoIha racional e do neoinstitucionalismo da escolha racional apresenta diferenças signi-

\footnotetext{
${ }^{5} \mathrm{Um}$ dos principais trabalhos que defendem essa postura é o de Giddens (1979). Está afirmação é de Peters (2003), eu a utilizo para possibilitar ao leitor a oportunidade de se situar melhor no debate.
} 
ficativas, que são, muitas vezes, desconsideradas ou mal compreendidas. A teoria da escolha racional se centra no indivíduo maximizador de benefícios pessoais. $O$ institucionalismo da escolha racional toma emprestado esse elemento comportamental e insere as instituições enquanto reguladoras das ações e condutas individuais e coletivas. Percebe-se, assim, que o institucionalismo da escolha racional possibilita a ampliação das análises sobre os arranjos institucionais pelo fato de combinar dois elementos anteriormente considerados antagônicos: indivíduos e instituições.

O casamento entre uma perspectiva comportamental e uma institucional representaram um avanço nos estudos sobre as instituições sociais, permeado pela formulação de críticas e a redefinição de conceitos e modelos analíticos que reduziam ou inviabilizavam análises da diversidade socioinstitucional. O esforço de problematizar as críticas e as sugestões de mudanças conceituais é fundamental para que se tenha clareza das limitações da teoria da escolha racional pura e se compreenda o institucionalismo da escolha racional.

\subsection{Limitações da teoria da escolha racio- nal}

O fato de ser uma teoria atraente não implica, necessariamente, que a teoria da escolha racional seja aceitável e geral (BOUDON, 1998; GREEN; SHAPIRO, 1994; OSTROM, 1998). Duas questões devem ser levantadas antes de atribuir à teoria da escolha racional o status de teoria geral: (1) nem todos os fenômenos e ações podem ser validamente explicados, (2) porque conforme apresenta Weber, a racionalidade se divide em dois tipos, a instrumental e a axiológica - a instrumentalidade da ação é limitada. Apesar das contestações nenhuma das estratégias utilizadas para considerar ações não instrumentais como ações instrumentais são convincentes, pois levantam mais questões do que respostas (BOUDON, 1998). Nesse sentido, Baert (1997) apresenta alguns pontos de limitação na teoria da escolha racional:

a) a distinção entre agir como se fosse racional e agir racionalmente. Os teóricos da escolha racional se defendem argumentando que a ideia de que as pessoas agem racionalmente é confirmada, empiricamente, através de modelos teóricos que permitem previsões sobre as ações das pessoas e sobre os efeitos destas ações. No entanto, isso não ocorre, porque a coerência entre o modelo e a realidade não é suficiente para confirmar a aplicabilidade das teorias da escolha racional que formam o modelo.

b) explicações a posteriori. Os teóricos da escolha racional, às vezes, dão sentido às práticas sociais atribuindo a elas racionalidade pós-fato. Isto é, demonstram que práticas que são irracionais prima facie são, num nível profundo, racionais. Com isso, imunizam suas teorias contra potenciais falsificações, visto que têm a racionalidade instrumental como pressuposto fundamental na construção de seus modelos.

c) racionalidade e cultura. Muitos teóricos tendem a ignorar ou equiparar a diversidade cultural. Ao adotarem esta postura, as preferências se mostram estáveis. A pressuposição da teoria da escolha racional que mais caracteriza a rejeição à cultura é a afirmação de que existe um único modo de agir, livre de qualquer especificação. Outro aspecto importante que é desconsiderado pelos modelos teóricos da escolha racional é a solidariedade, que permeia as relações 
entre os indivíduos de uma sociedade ou grupos sociais (DOUGLAS, 2007).

\subsection{Alternativas às limitações}

A fim de questionar o postulado básico da teoria da escolha racional, a racionalidade, Boudon (1998) recorre aos trabalhos de Tocqueville e de Weber. A partir do primeiro, elabora o conceito de racionalidade cognitiva, que se distingue da racionalidade instrumental por dois aspectos: (1) porque defende uma ação não instrumental; e (2) porque a ação do ator não visa a maximização de benefícios e a minimização de custos, mas, verificar se uma ideia é aceitável ou não. Do segundo resgata a definição de racionalidade axiológica, que prediz que, numa determinada situação os indivíduos fazem $X$ não porque eles esperam qualquer consequência desejável, mas porque estão convencidos de que $X$ é bom.

Ao sugerir a introdução destes dois tipos de racionalidade, Boudon (1998) propõe, a partir de Tocqueville e Weber, um modelo cognitivista ${ }^{6}$, baseado no seguinte postulado: até que se prove o contrário, os atores devem ser considerados racionais, porque eles têm fortes razões para acreditar nisso; em alguns casos, estas razões podem ser tratadas como diferenças entre custo e benefício de linhas alternativas de ação; em outras circunstâncias o centro de uma ação é constituído por razões axiológicas. Seguindo esse raciocínio a teoria da escolha racional é um caso especial de modelo cognitivista.

Para Ostrom (1998), os modelos de racionalidade completa foram importantes para explicar situações em que os atores

${ }^{6} \mathrm{O}$ termo em inglês é Cognitivist Model. sociais que não maximizam seus benefícios são eliminados. Entretanto, por ser uma teoria comportamental, a escolha racional deveria ter considerado o complexo processo de aprendizado de regras e de normas, como um elemento que permite o alcance de resultados melhores. Partindo desse pressuposto, a autora propõe um modelo de racionalidade fundamentado no aprendizado de regras e normas, porque poucas situações na vida geram informações suficientes para fazer uma ótima escolha.

Baert (1997) propõe um quadro conceitual alternativo que tem em comum com os teóricos da escolha racional a ideia de que as pessoas podem visualizar as consequências de suas ações. Contudo, sua perspectiva difere da teoria da escolha racional, especificamente, por considerar que a noção de racionalidade livre da cultura é muito problemática e, por isso, sugere a noção de autorreflexão de segunda ordem, que se refere à habilidade das pessoas elaborarem um conhecimento teórico que respeite as condições, os efeitos, as regras e as premissas fundamentais de suas ações.

\subsection{Ampliação do método da escolha ra- cional: construção da abordagem institu- cional}

A formação do institucionalismo da escoIha racional deriva de recursos teóricos da nova economia da organização. As primeiras aplicações teóricas remetem a estudos no interior do Congresso Norte-Americano que procuravam observar a aplicabilidade do postulado clássico da teoria da escolha racional (HALL; TAYLOR, 2003): se as escoIhas são exatas, é difícil reunir maiorias estáveis para votar leis no Congresso, onde as preferências dos legisladores deveriam ge- 
rar ciclos, nos quais cada nova maioria invalidaria as leis propostas pela maioria precedente. Contudo, as decisões possuíam um notável grau de estabilidade.

As respostas para a estabilidade das decisões tomadas pelo Congresso NorteAmericano foram buscadas nas instituições. A existência de maiorias estáveis era decorrente das regras de procedimento e das comissões do Congresso que estruturavam as informações disponíveis aos seus membros e as escolhas. Essas regras permitiam, por exemplo, fixar a pauta, o que limitava as decisões a serem submetidas ao voto. 0 Congresso diminuiu os custos de transação necessários à conclusão dos acordos, porque as instituições auxiliaram na resolução dos problemas de ação coletiva enfrentados pelos legisladores (HALL; TAYLOR, 2003).

A partir da década de 1990, os teóricos da escolha racional passaram a se interessar pela análise de outros fenômenos políticos, tais como: o desenvolvimento histórico das instituições políticas de países em transição política (PRZEWORSKI, 1994), as reformas institucionais realizadas por países da União Europeia (TSEBELIS, 1994), a decisão do voto na manutenção da liberdade política (FIGUEIREDO, 1991), entre outros, ampliando, assim, as possibilidades de análises políticas.

O institucionalismo da escolha racional possui uma diversidade de pontos de vistas sobre as instituições, às vezes, desconsiderados, o que leva alguns autores a agrupálos em um só, como o fez Green e Shapiro (1994). Apresentarei três variações do institucionalismo da escolha racional: (1) o modelo baseado na relação chefe-agente; (2) o modelo baseado na teoria dos jogos; e (3) os modelos baseados nas regulamentações. Embora estes modelos sejam internamente distintos, apresentam propriedades fundamentais comuns.

a) modelo chefe-agente. Esse modelo pode ser aplicado na análise de organizações e pode auxiliar na compreensão das interações entre grupos de instituições reguladoras do setor público ${ }^{7}$. Contudo, possui duas limitações principais: não elucida como desenhar uma estrutura em que o chefe possa ter certeza de que o agente satisfaz os requisitos do chefe; e, simplifica a complexa natureza da política reguladora, ao se deter apenas ao desenho institucional e deixar de lado as mudanças no direito administrativo que alteram o comportamento das instituições reguladoras.

b) modelos baseados na teoria dos jogos. A teoria institucional baseada na teoria dos jogos tem muito em comum com a do chefe-agente. Ambas se concentram no problema do cumprimento das normas ou instruções, supondo, por exemplo, que os legisladores procuram identificar maneiras de evitar que os burocratas abandonassem seus compromissos. Porém, para a teoria dos jogos, o problema é bilateral, e não unilateral como no modelo do chefe-agente, ou seja, cada um dos grupos de atores tenta compreender o outro para que escolha sua tática de negociação.

c) modelos baseados em regulamentações. Consideram as instituições como estratégias que $\mathrm{o}$ ator racional utiliza para aumentar o seu benefício pessoal (DOWNS, 1999), ou como as regras que influenciam nas condutas individuais, por meio de sanções e incentivos (OLSON, 1999), por meio do aprendizado de normas e de regras de

${ }^{7}$ Os estudos baseados neste modelo têm analisado as políticas reguladoras das comissões do Congresso Norte-Americano (COOK; WOOD, 1989). 
reciprocidade e da confiança (OSTROM, 1990, 1998) ou a partir de restrições criadas pelos homens para facilitar a interação humana (NORTH, 1990). Neste sentido, esse modelo contribui para elucidação do problema fundamental da ação coletiva, os dilemas sociais.

Regras, normas e indivíduos racionais são os pilares do institucionalismo da escolha racional. A relação destes componentes possibilitou às ciências sociais a análise pormenorizada do papel das instituições no desenvolvimento de comunidades, cidade, regiões e países, bem como o papel desempenhado pelos indivíduos e membros das instituições, nesse processo. Além disso, abriu caminho para a formulação de modelos teóricos que possibilitaram a análise do desempenho das instituições sociais e sua relação com o desenvolvimento local.

\section{A DINÂMICA DO DESEMPENHO INSTITU- CIONAL}

A avaliação do desempenho de instituições se constitui um elemento preponderante do neoinstitucionalismo, devido a três aspectos: (1) como as instituições moldam a política? (2) como instituições são moldadas pela história? e, por fim, (3) em que medida as instituições são influenciadas pelo contexto social em que atuam? O que permite tomar as instituições como variável independente, investigando empiricamente como a mudança institucional influencia na identidade, no poder e nas estratégias dos atores políticos; e, como variável dependente, a partir da averiguação de como o desempenho institucional é condicionada pela história? (PUTNAM, 2002).

A análise do desempenho institucional se inicia com o entendimento (OSTROM, 2006) de: (1) por que as instituições são criadas e mantidas? e (2) quais consequências elas geram nos diversos locais em que estão inseridas? Neste sentido, o desempenho institucional se refere a questões relacionais. Sua mensuração visa, portanto, a comparação do papel das instituições sociais, por exemplo, na formulação e execução de políticas públicas, na melhoria da qualidade de vida, no desenvolvimento local, entre outros.

A tentativa de compreensão da dinâmica do desempenho institucional não é nova na ciência social. Na literatura referente à temática, existem, pelo menos, três maneiras de explicar esse desempenho (PUTNAM, 2002):

a) a primeira corrente, derivada dos estudos jurídicos formais emergentes da efervescência constitucionalista do século XIX, enfatiza o projeto institucional. Atualmente, defensores e reformadores pragmáticos do neoinstitucionalismo passaram a dar atenção aos determinantes organizacionais do desempenho institucional.

b) a segunda corrente enfatiza os fatores socioeconômicos. Desde Aristóteles, sociólogos e políticos afirmam que uma verdadeira democracia depende do desenvolvimento social e do bem-estar econômico dos cidadãos.

c) a terceira corrente destaca a importância dos fatores socioculturais no desempenho das instituições democráticas. Almond e Verba (1963) utilizaram a noção de cultura cívica para explicar as diferenças de governo democrático nos Estados Unidos, na Grã-Bretanha, na Itália, no México e na Alemanha.

Putnam (2002), ao analisar a relação entre o desempenho dos governos regionais da Itália e o desenvolvimento local, levanta 
duas questões: (1) em que medida os contextos social, econômico e cultural interferem no desempenho institucional? (2) quais são as condições necessárias para a criação de instituições fortes e eficazes? Para obter elementos que possibilitassem a explicação destes questionamentos, o autor realizou uma comparação entre os governos regionais, mediante a análise dos ambientes sociais, econômicos, culturais e políticos, tomando o neoinstitucionalismo como ferramenta teórica e metodológica.

A definição de desempenho institucional elaborada por Putnam (2002) para avaliar os governos regionais da Itália foi a seguinte: demandas sociais $\rightarrow$ interação política $\rightarrow$ governo $\rightarrow$ opção de política $\rightarrow$ implementação. Além disso, procurou: (1) ser abrangente, pois as instituições realizam várias tarefas; (2) ser internamente coerente, porque só poderemos falar em êxito ou fracasso se todos os indicadores permitirem essa constatação; (3) corresponder aos objetivos e aos critérios dos protagonistas; e, (4) verificar a capacidade da instituição em empreender ações coletivas coordenadas para o provimento de benefícios coletivos.

O quarto requisito é de suma importância porque as instituições têm a tarefa de prover benefícios comuns ou coletivos aos seus membros. Os benefícios comuns são usualmente chamados de benefícios públicos (OLSON, 1999). Um benefício público, coletivo ou comum, é aquele que se for consumido por uma pessoa $X_{i}$ em um grupo $X_{1}, \ldots, X_{i}, \ldots, X_{n}$, não pode ser negado a nenhum dos demais membros desse grupo. $O$ fornecimento de bens públicos é caracteristicamente institucional, já que os benefícios não coletivos comuns sempre podem ser alcançados a partir da ação individual.

O processo de aquisição de um bem pú- blico traz consigo uma contradição entre racionalidade individual e racionalidade coletiva. Embora todos os membros de uma instituição queiram adquirir o bem público, eles não têm nenhum interesse comum em pagar o custo do provimento do mesmo. Esse fenômeno é definido como dilemas sociais ou da ação coletiva. A resolução desses dilemas, segundo Olson (1999), dar-seia mediante a atuação de um interventor externo que estimularia os indivíduos racionais a agirem de forma coletiva.

Ostrom (1990, 1994, 1998) constatou empiricamente que as propriedades comuns, como áreas de floresta e estoques pesqueiros, poderiam ser geridas com sucesso pelos próprios usuários, refutando, assim, a tese de que a gestão de recursos naturais deve ser estatal ou privada. O modelo teórico construído pela autora se contrapõe, portanto, à proposta de Olson (1999), ao ressaltar que reciprocidade e confiança possibilitam a superação dos dilemas de ação coletiva, sem a necessidade de incentivos ou sanções externas.

A resolução de dilemas sociais sem a necessidade do fornecimento de incentivos ou imposição de sanções se materializa na participação dos processos de tomada de decisão; na igualdade política, ou seja, direitos e deveres iguais para todos e, nas relações horizontais de reciprocidade; na solidariedade, confiança e tolerância. Essas características são, na verdade, os mecanismos institucionais, informais e formais, que instituições adotam para alcançarem resultados que satisfaçam aos seus membros.

Participação, igualdade política, solidariedade, confiança e tolerância, referem-se ao estoque de capital social da comunidade. O capital social constitui-se um bem público caracterizado por relações horizontais de 
reciprocidade que são desenvolvidas ao longo do tempo entre os membros de um dado grupo social (PUTNAM, 2000, 2002; PUTNAM, FELDSTEIN; COHEN, 2003). O que possibilita ações voluntárias que facilitam a superação de dilemas de ação coletiva e o oportunismo dos indivíduos, aspectos tão caros ao estímulo da cooperação.

As regras de reciprocidade podem ser de dois tipos (PUTNAM, 2002): reciprocidade balanceada, que diz respeito à permuta simultânea de itens de mesmo valor, e reciprocidade generalizada, que se refere a uma contínua relação de troca que, comumente, apresenta desequilíbrio ou falta de correspondência. O segundo tipo de reciprocidade é altamente produtivo para o capital social. Nas comunidades em que essa regra é obedecida, o oportunismo é coibido e os problemas de ação coletiva são solucionados. A reciprocidade generalizada, geralmente, está associada a um amplo sistema de intercâmbio social.

\section{CONSIDERAÇÕES FINAIS}

No momento em que a cooperação é constantemente defendida nos debates políticos e acadêmicos - nas agendas das câmaras municipais, estaduais e no Congresso Nacional e nas questões relacionados ao desenvolvimento local -, as instituições desempenham um papel importante, no sentido regulamentar comportamentos e moldar condutas a partir das regras e normas que as constituem, que podem ser exemplificadas nas discussões em torno do novo Código Florestal, das Reformas Política, Trabalhista e da Previdência, e na criação e reestruturação de órgãos públicos municipais, estaduais e federais de fiscalização.
O neoinstitucionalismo ocupa um lugar de destaque nesse cenário, ao retomar os debates sobre as instituições sociais fornece métodos analíticos capazes de propiciar a realização de estudos amplos e variados sobre as dinâmicas institucionais que perpassam a nossa vida cotidiana. É indispensável ter clareza que o neoinstitucionalismo não é uma proposta teórica unificada, por isso se fez uma viagem exploratória pelas abordagens institucionais e comportamentais, individualmente, e depois se deteve ao casamento entre o institucionalismo e a teoria da escolha racional para apresentar uma abordagem que ampliou o foco de análise: o institucionalismo da escolha racional.

A revisão de literatura realizada fornece elementos para a análise do desempenho de instituições sociais de diferentes escopos, informais, formais, públicas e privadas, ao tratar da reciprocidade, da confiança e dos mecanismos formais que procuram estimular a cooperação voluntária e não voluntária, mediante a redução das incertezas e dos custos sociais. Nesse sentido, o neoinstitucionalismo não se apresenta como um modelo teórico abstrato que procura enquadrar o objeto de pesquisa numa camisa de força, impossibilitando a compreensão da diversidade institucional. Pelo contrário, incorpora aspectos sociais, econômicos, políticos e culturais.

\section{REFERÊNCIAS}

ALMOND, G. A.; VERBA, S. The civic culture: political attitudes and democracy in five nations. Princeton, Princeton University Press, 1963.

ARROW, K. Social choice and individual values. New Haven, Yale University Press, 
1951.

BAERT, P. Algumas limitações das explicações da escolha racional na ciência política e na sociologia. Revista Brasileira de Ciências Sociais, São Paulo, v. 12 , n. 35 , p. 6374, fev. 1997.

BOUDON, R. Ação. In: - Tratado de Sociologia. Rio de Janeiro, Jorge Zahar, 1995. Limitations of rational choice theory. The American Journal of Sociology, v. 104, n. 3, p. 817-828, Nov. 1998.

CANIELLO, M.; PIRAUX, M.; BASTOS, V. V. S. Capital social e desempenho institucional no colegiado territorial da Borborema, Paraíba. Raízes, Campina Grande, v. 32, n. 2, p. 11-31, jul./dez. 2012.

CAVALCANTE, P. Descentralização de políticas públicas sob a ótica neoinstitucional: uma revisão de literatura. Revista de Administração Pública, Rio de Janeiro, v. 45, n. 6, p. 1781-1804, nov./dez. 2011.

COOK, B.; WOOD, B. D. Principal-agent models of political control of the bureaucracy. American Political Science Review, v. 83, n. 3, p. 965-978, Sept. 1989.

DIMAGGIO, P. J.; POWELL, W W. Introdução. In: El nuevo institucionalismo en el análisis organizacional. México, Fondo de Cultura Económica, 1999, p. 33-75. DOUGLAS, M. Como as instituições pensam. São Paulo, EDUSP, 2007.

DOWNS, A. Uma teoria econômica da democracia. São Paulo, EDUSP, 1999.

ELSTER, J. Marxismo, funcionalismo e teoria dos jogos: argumentos em favor do individualismo metodológico. Revista Lua Nova, São Paulo, n. 17, p. 163-204, jun. 1989.

Peças e engrenagens das ciências sociais. Rio de Janeiro, Relume-Dumará, 1994.

FELISBERTO, E. Da teoria à formulação de uma Política Nacional de Avaliação em Saúde: reabrindo o debate. Ciência \& Saúde Coletiva, Rio de Janeiro, v. 11, n. 3, p. 553563, jul. 2006.

FEREJOHN, J.; PASQUINO, P. A teoria da escolha racional na ciência política: conceitos de racionalidade em teoria política. Revista Brasileira de Ciências Sociais, São Paulo, v. 16, n. 45, p. 05-24, fev. 2001.

FERNANDES, A. S. A. O capital social e a análise institucional e de políticas públicas. Revista de Administração Pública, Rio de Janeiro, v. 36, n. 3, p. 375-398, maio/jun. 2002.

FIGUEIREDO, M. A. decisão do voto: democracia e racionalidade. São Paulo, ANPOCS, 1991.

GIDDENS, A. Central problems in social theory: action, structure and contradiction in social analysis. Berkeley: University of California Press, 1979.

GREEN, D. P.; SHAPIRO, I. Pathologies of rational choice theory: a critique of applications in political science. New Haven and London: Yale University Press, 1994.

HALL, P. A.; TAYLOR, R. C. R. As três versões do neo-institucionalismo. Revista Lua Nova, São Paulo, n. 58, p. 194-223, 2003.

KATO, J. Institutions and rationality in politics: three varieties of neo-institutionalists. British Journal of Political Science, Cambridge, v. 26, n. 4, p. 553-583, Oct. 1996.

KISER, L.; OSTROM, E. The three words of action: a metatheoretical syntehesis of institutional approaches. In: OSTROM, E. (Comp.). Strategies of political inquiry. California: Sage, 1982, p. 179-222.

MACKE, J.; SARATE, J. A. R. Desenvolvimento territorial e capital social: elementos, conexões e proposta de avaliação de territórios. Revista Brasileira de Gestão e Desenvolvimento Regional, Taubaté, v. 11, n. 
3, p. 56-79, set./dez. 2015.

MARCH, J. G.; OLSEN, J. P. Rediscovering institutions. New York: Free Press, 1989.

The new instittutionalism: organizational factors in political life. American Political Science Review, Washington, $\mathrm{n}$. 78, p. 738-749, Sept. 1984.

MARQUES, E. C. Notas críticas a literatura sobre Estado, políticas estatais e atores políticos. BIB: Revista Brasileira de Informação Bibliográfica em Ciências Sociais, São Paulo, v. 43, p. 67-102, 1997.

MENDES, A.; CODATO, A. The institutional configuration of sport policy in Brazil: organization, evolution and dilemmas. Revista de Administração Pública, Rio de Janeiro, v. 49, n. 3, p. 563-593, maio/jun. 2015.

MEYER, J. W.; ROWAN, B. Institutionalizing organizations: formal structure as myth and ceremony. American Journal of Sociology, Chicago, v. 83, n. 2, p. 340-363, Sept. 1977. MIRANDA, R. S. Desempenho institucional e a superação dos dilemas sociais em assentamentos do semi-árido paraibano. 2007. 145f. Dissertação (Mestrado em Sociologia) - Centro de Humanidades, Universidade Federal de Campina Grande, Campina Grande, 2007.

MONTEIRO, J. C. S.; MONTEIRO, M. C. M. C.; LIMA, T. L. O neo-institucionalismo e o viés antipartidário nos estudos legislativos. Adcontar, Belém, v. 2, n. 1, p. 7-10, 2001.

NORTH, D. C. Institutions, institutional change and economic performance. Cambridge: Cambridge University Press, 1990.

OLSON, M. Lógica da ação coletiva. São Paulo, EDUSP, 1999.

OSTROM, E. Governing the commons: the evolution of institutions for collective action. New York, Cambridge University Press, 1990.

Rules, games, and common-pool resources. Michigan, University of Michigan, 1994.

OSTROM, E. A behavioral approach to the rational choice theory of collective action. American Political Science Review, Washington, v. 92, n. 01, p. 1-21, Mar. 1998. . Understanding institutional diversity. Princeton, Princeton University Press, 2006.

PERES, P. S. Comportamento ou instituições? A evolução histórica do neoinstitucionalismo da ciência política. Revista Brasileira de Ciências Sociais, São Paulo, v. 23, n. 68, p. 53-192, out. 2008.

PERES, P.; CARVALHO, E. Religando as arenas institucionais: uma proposta de abordagens multidimensionais nos estudos legislativos. Revista de Sociologia e Política, Curitiba, v. 20, n. 43, p. 81-106, out. 2012. PETERS, B. G. El nuevo institucionalismo: teoria institucional en ciencia política. Barcelona: Gedisa, 2003.

PRZEWORSKI, A. Democracia e mercado: reformas políticas e econômicas na Europa Oriental e na América Latina. Rio de Janeiro: Relume-Dumará, 1994.

PUTNAM, R. D. Bowling alone: the collapse and revival of american community. New York, Simon and Schuster, 2000.

. Comunidade e democracia: a experiência da Itália moderna. 3. ed. Rio de Janeiro: FGV, 2002.

PUTNAM, R. D.; FELDSTEIN, L. M.; COHEN, D. Better together: restoring the american community. New York, Simon and Schuster, 2003.

ROMERO, J. J. Los nuevos institucionalismos: sus diferencias, sus cercanías. In: POWELL, W. W.; DIMAGGIO, P. J. (Comp.). El nuevo institucionalismo en el análisis organizacional. México: Fondo de Cultura Econômica, 1999, p. 7-29. 
TSEBELIS, G. The Power of the European Parliament as a Conditional Agenda Setter. American Political Science Review, Washington n. 88, p. 795-815, Mar. 1994. . Jogos ocultos: escolha racional no campo da política comparada. São Paulo: EDUSP, 1998.

VIEIRA, D. M.; GOMES, R. C. Mudança Institucional Gradual e Transformativa: a Influência de Coalizões de Advocacia e Grupos de Interesses em Políticas Públicas. Organização \& Sociedade, Salvador, v. 21, n. 71, p. 679-694, dez. 2014.

ZAFIROVSKI, M. What is really rational choice? Beyond the utilitarian concept of rationality. Current Sociology, Madrid, v. 47, n. 1, p. 47-113, Jan. 1999.

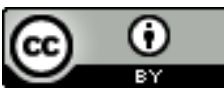

License information: This is an openaccess article distributed under the terms of the Creative Commons Attribution License, which permits unrestricted use, distribution, and reproduction in any medium, provided the original work is properly cited.

Artigo recebido em 16 de agosto de 2017.

Avaliado em 14 de setembro de 2017.

Aceito em 18 de setembro de 2017.

Publicado em 22 de setembro de 2017.

\section{Como citar este artigo (ABNT):}

MIRANDA, Roberto de Sousa. Uma revisão de literatura sobre o neoinstitucionalismo e a avaliação do desempenho de instituições sociais. Estação Científica (UNIFAP), Macapá, v. 7, n. 2, p. 59-75, maio/ago. 2017. 